\title{
The Potential Emergence of Disease-Modifying Treatments for Alzheimer Disease: The Role of Primary Care in Managing the Patient Journey
}

\author{
Jenny Lam, MD, MAS, Jakub Hlávka, PhD, and Soeren Mattke, MD, DSc
}

Despite recent setbacks, disease-modifying treatments (DMTs) for Alzheimer disease (AD) might become available within a few years. These DMTs are likely to be used in the early stages of AD to avoid the progression to manifest dementia, which implies that a large reservoir of prevalent cases would need to be evaluated when DMTs first become available. Primary care providers (PCPs) would play a vital role in managing the patient flow to specialty care. We review the literature on diagnostic tests that could be used by PCPs and estimate the impact of different testing approaches on demand for specialty care.

While many tests have been evaluated, only the Mini-Mental State Examination (MMSE) and the Montreal Cognitive Assessment (MoCA) perform acceptably for detection of early-stage cognitive decline with sensitivities and specificities of $55 \%$ to $82 \%$ and $72 \%$ to $84 \%$, respectively, for the MMSE; and $77 \%$ to $96 \%$ and $73 \%$ to $95 \%$, respectively, for the MoCA. However, neither test is sufficiently specific for the AD pathology and would result in 4 to 5 false positives for each true positive. Blood-based tests for AD biomarkers may soon become available for clinical use. A plasma amyloid- $\beta$ (Aß) test has been shown to have a sensitivity of up to $97 \%$ and specificity of up to $81 \%$. Adding this test to the MMSE or MoCA could reduce false positives by approximately $80 \%$.

These findings suggest a combination of brief cognitive tests and blood-based biomarker tests will allow PCPs to identify patients with potential early stage AD efficiently and triage them for further evaluation. (J Am Board Fam Med 2019;32:931-940.)

Keywords: Alzheimer Disease, Amyloid Beta-Peptides, Biomarkers, Cognitive Dysfunction, Dementia, Diagnostic Tests, Disease Progression, Mental Status and Dementia Tests, Primary Health Care, Sensitivity and Specificity

Despite multiple setbacks, such as the recent termination of the clinical trial program for aducanumab, there is still hope that a disease-modifying treatment (DMT) for Alzheimer disease (AD) will become available within the next few years. ${ }^{1}$

This article was externally peer reviewed.

Submitted 5 November 2018; revised 27 June 2019; accepted 27 June 2019.

From the Leonard D. Schaeffer Center for Health Policy and Economics, University of Southern California, Los Angeles, CA (JM); Price School of Public Policy, University of Southern California, Los Angeles, CA (JH); Center for Economic and Social Research, University of Southern California, Los Angeles, CA (SM).

Funding: This project was funded by Biogen Inc.

Conflict of interest: SM serves on the board of directors of Senscio Systems, Inc. and the scientific advisory board of aicure technologies, Boston Millennia Partners and ZanoZano. He has received consulting fees from AARP, Biotronik, Bristol-Myers Squibb, and Defined Health. JL and JH report no financial conflicts of interest.
For example, BAN2401 was the first candidate treatment that has shown an effect on cognitive decline in a recently published Phase II trial. ${ }^{2}$ These DMTs or other medications are likely to be used in the early stages of $\mathrm{AD}$ to prevent progression to manifest dementia. This preventive treatment paradigm means that a substantial number of patients would need to be evaluated, diagnosed, and treated for early-stage disease. The number of patients would be particularly large when DMTs first became available because of the large reservoir of

Prior Presentation: Presented in part at the 2019 Alzheimer's Association International Conference, Los Angeles, July 14-18, 2019 and at the Lausanne VI Workshop, Lausanne, Switzerland, November 13-14, 2019.

Corresponding author: Soeren Mattke, MD, DSc, Center for Economic and Social Research, University of Southern California, 635 Downey Way, VPD 505N, Los Angeles, CA 90089, (E-mail: mattke@usc.edu). 
Figure 1. Biological model of Alzheimer disease.

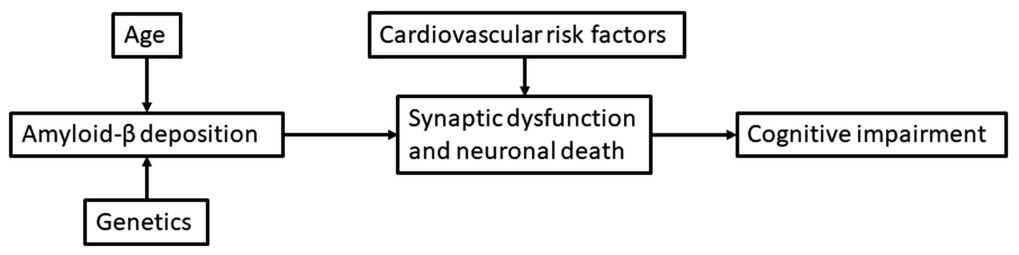

prevalent cases. A recent study has shown that the US health care system is ill prepared to meet this demand because of a lack of specialists and diagnostic and treatment centers. ${ }^{3}$ Estimated wait times of up to 19 months could potentially lead to around 2.1 million patients progressing to Alzheimer's dementia while waiting for treatment. Even in the absence of a treatment, the demand for diagnostic evaluation of cognitive impairment will increase with population ageing and emerging evidence that a correct diagnosis alone changes clinical management. ${ }^{4,5}$

Situated early in the care pathway, primary care providers will play a vital role in managing the patient flow to specialty care, as they will be responsible for triaging patients for further evaluation. To carry out this responsibility, primary care providers need proper tools, guidance, time, and reimbursement. This article will focus on the tools for the evaluation of cognitive impairment in the primary care setting. We present an overview of the pathobiology of $\mathrm{AD}$, the DMTs in development and the diagnostic process with an emphasis on diagnostic tools for primary care providers, and simulate the impact of different of different approaches to the initial evaluation in the primary care setting on demand for specialty evaluation and treatment.

\section{Pathobiology of AD}

$\mathrm{AD}$ is a progressive neurodegenerative disease that is the most common cause of dementia in the United States, where the estimated prevalence of Alzheimer's dementia is $14.5 \%$ in adults over 65 years old. ${ }^{6}$ Amyloid- $\beta$ (A $\beta$ ) plaques and neurofibrillary tangles of $\tau$ protein are the cardinal pathologic features that distinguish $\mathrm{AD}$ from other etiologies of dementia. The amyloid hypothesis (Figure 1) states that $A \beta$ plaques, which can be detected by positron emission tomography (PET) scan with the Pittsburgh $\mathrm{B}(\mathrm{PiB})$ radiotracer (also known as the PiB-PET scan) or testing for $A \beta$ levels in cerebrospinal fluid (CSF), build up in the brain due to an imbalance of $A \beta$ production and clearance. They contribute to the formation of neurofibrillary tangles of $\tau$ protein and other downstream processes that eventually lead to neuronal death. ${ }^{7}$ As more neurons die, the patient will start exhibiting cognitive impairment. While the core clinical manifestation of $\mathrm{AD}$ is episodic memory impairment, other cognitive domains may also be affected, especially as the disease progresses. ${ }^{8,9}$

The diagnosis of $\mathrm{AD}$ is based on its biological hallmarks, and patients are classified into 3 stages based on clinical presentation: preclinical $\mathrm{AD}$, mild cognitive impairment (MCI) due to $\mathrm{AD}$, and $\mathrm{Alz}^{-}$ heimer's dementia (Figure 2). ${ }^{9}$ During the preclinical stage, there is no perceptible cognitive impairment, but changes in biomarkers, such as $\mathrm{A} \beta$, are detectable by CSF testing and imaging. This preclinical stage may precede cognitive impairment by as much as 20 years. ${ }^{10,11}$ The next stage of $\mathrm{AD}$ is characterized by MCI that is detectable with neuropsychological exams; day-to-day occupational and social functioning are mostly preserved. , $^{8,12,13}$ The final stage of $\mathrm{AD}$ is dementia, which can be further subclassified into mild, moderate, and severe depending on the impact on activities of daily living. ${ }^{9}$

\section{Disease-Modifying Treatments in Development}

Disease-modifying treatments (DMTs) target the pathogenic pathway of $\mathrm{AD}$ to delay the onset or progression of dementia. Unlike currently available symptomatic treatments, they need to be initiated before the development of moderate-to-severe dementia, implying a need to identify patients early in the disease process.

The DMTs in these active clinical trials (Table 1) $)^{14-23}$ target either the amyloid or $\tau$-pathogenic pathways, but there are drugs with other mechanisms of action in the earlier stages of development. ${ }^{24,25}$ The earliest expected primary completion date for Phase III trials is in July 2022, 
Figure 2. Classification of patients in Alzheimer disease. MCI, mild cognitive impairment.

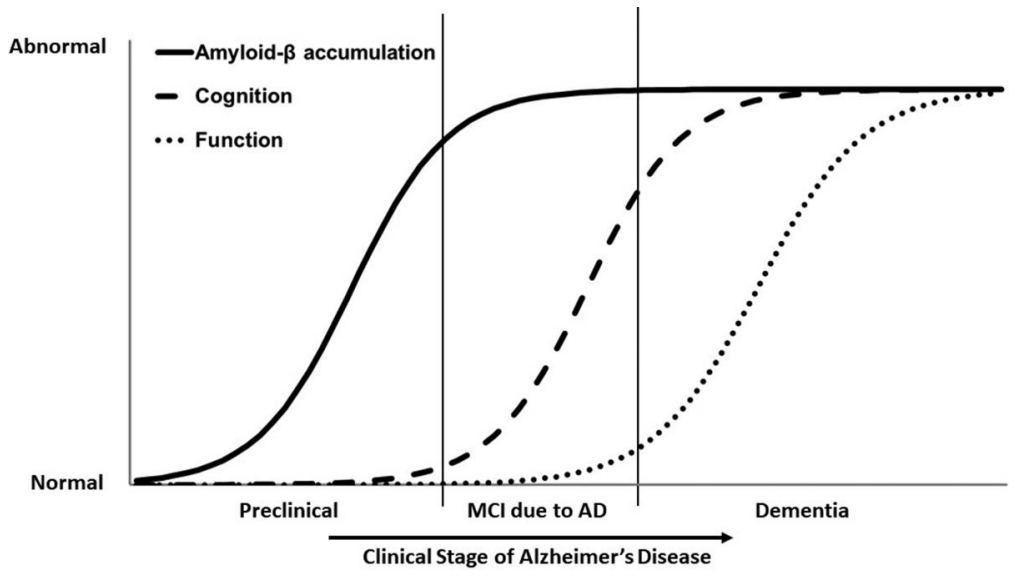

which suggests that DMTs may become commercially available as early as 2023 .

\section{Diagnostic Evaluation of Mild Cognitive Impairment}

As the 2018 American Academy of Neurology guideline recommends, establishing a diagnosis of mild cognitive impairment (MCI) through validated tests is important because clinicians could provide important care through counseling, management of modifiable risks and nonpharmacological treatments, even in the absence of a DMT. ${ }^{26}$

The diagnostic process to evaluate cognitive function starts with short cognitive tests to detect or confirm early-stage impairment, most likely in primary care settings. Primary care providers might additionally look for alternative causes for the impairment and complicating factors that may affect the management of the patient, such as depression, cerebrovascular disease and medication and alcohol use. They would also document family history and potentially assess genetic risk.

Confirmatory diagnostic testing of MCI and identification of the underlying pathology will likely require the expertise of dementia specialists because of the complexity of the required tests and the differential diagnosis. A comprehensive neuropsychological test battery may be performed by specialists to verify and detail the degree and pattern of the cognitive impairment. Biomarker test-

Table 1. Disease-Modifying Treatments for Alzheimer's Disease in Phase 2 and Phase 3 Clinical Trials

\begin{tabular}{|c|c|c|c|}
\hline Candidate & $\begin{array}{l}\text { Clinical Trial } \\
\text { Phase }\end{array}$ & $\begin{array}{l}\text { Expected Primary } \\
\text { Completion Date }\end{array}$ & $\begin{array}{l}\text { National Clinical } \\
\text { Trial Identifier }\end{array}$ \\
\hline \multicolumn{4}{|l|}{ Anti-A $\beta$ antibodies } \\
\hline Gantenerumab & Phase 3 & May-22 & $\begin{array}{l}\text { NCT03443973, } \\
\text { NCT03444870 }\end{array}$ \\
\hline BAN2401 & Phase 3 & Jul-22 & NCT03887455 \\
\hline LY3002813 & Phase 2 & Oct-20 & NCT03367403 \\
\hline \multicolumn{4}{|l|}{ Anti-tau antibodies } \\
\hline $\mathrm{ABBV}-8 \mathrm{E} 12$ & Phase 2 & Dec-20 & NCT02880956 \\
\hline RO7105705 & Phase 2 & Sep-20 & NCT03289143 \\
\hline \multicolumn{4}{|l|}{ BACE inhibitors } \\
\hline Elenbecestat (E2609) & Phase 3 & Jun-21 & NCT03036280 \\
\hline CNP520 & Phase $2 / 3$ & Jul-24 & NCT03131453 \\
\hline \multicolumn{4}{|l|}{ Vaccines } \\
\hline CAD106 & Phase $2 / 3$ & Aug-24 & NCT02565511 \\
\hline AADvac1 & Phase 2 & Jun-19 & NCT02579252 \\
\hline
\end{tabular}

$\mathrm{A} \beta$, amyloid-beta; BACE, Beta-secretase.

Clinical trial information was obtained from ClinicalTrials.gov as of June 27, 2019. 
ing with either CSF analysis or PET imaging can be done to diagnose $\mathrm{AD}$ as the underlying etiology, but both tests are typically not yet available or covered outside of clinical research. ${ }^{8}$ Cases with mixed etiology can present with a complex pattern of symptoms and biomarker and imaging findings. Furthermore, patients with MCI may remain stable or revert to normal cognition in some cases. Given these variabilities and complexities in the disease presentation, specialists are better equipped to sort out these clinical and biomarker findings to work through the differential diagnoses and, should a DMT become available, assess the patient for treatment indications. Because specialist evaluation is complex, costly, and capacity constrained, optimizing evaluation at the primary care level is critical to reduce wait times.

\section{Brief Cognitive Tests for MCI}

Organizations like the Alzheimer's Association ${ }^{27}$ and the Gerontological Society of America ${ }^{28}$ are recommending various screening tests, such as the General Practitioner Assessment of Cognition and the Mini-Cog, to be used, for example, for cognitive assessment as part of the Annual Wellness Visit. These instruments have been validated for detection of dementia but not of MCI. ${ }^{29-31}$

Beyond the General Practitioner Assessment of Cognition and Mini-Cog, there are a number of cognitive tests that have been proposed for evaluating MCI, but-similar to previous reviews-we found limited evidence supporting the use of most of these cognitive tests. ${ }^{29-33}$ The best researched and most widely used tests in the United States to date are the mini-mental state examination (MMSE) and the Montreal Cognitive Assessment (MoCA). These tests are potentially suitable for use in primary care settings; as they take only approximately 10 to 15 minutes to administer and score without the need for dedicated equipment or specially trained personnel. They test multiple cognitive domains, but differ in how each of the domains are weighted (Table 2), which may influence their performance in detecting MCI. ${ }^{34}$

\section{MMSE}

The MMSE was originally developed to assess the cognitive function of elderly, hospitalized patients with a wide range of health conditions, not specific for dementia. ${ }^{35}$ There is considerable variability in the reported diagnostic performance of the MMSE
Table 2. Comparison of the Scoring of Cognitive Domains by the MMSE and MoCA

\begin{tabular}{lcc}
\hline Cognitive Domain & $\begin{array}{c}\text { MMSE } \\
\text { (Maximum } \\
\text { Score) }\end{array}$ & $\begin{array}{c}\text { MoCA } \\
\text { (Maximum } \\
\text { Score) }\end{array}$ \\
\hline Orientation: time and place & 10 & 6 \\
Registration & 3 & - \\
Attention and concentration & 5 & 6 \\
Memory & 3 & 5 \\
Verbal fluency & - & 1 \\
Language & 8 & 5 \\
Visuospatial abilities & 1 & 5 \\
Abstraction & - & 2 \\
Total score & 30 & 30 \\
\hline
\end{tabular}

MMSE, Mini-Mental State Exam; MoCA, Montreal Cognitive Assessment.

for MCI and dementia due to the heterogeneity of the patient samples, the cutoff scores, and the diagnostic criteria. ${ }^{29,31,36}$ Systematic reviews have reported that the MMSE performs relatively well in identifying possible Alzheimer's dementia, but its ability to detect MCI has been found to be suboptimal. ${ }^{29,31}$

There are several possible reasons for the limited performance of the MMSE to detect MCI: The memory and executive functioning tasks are underrepresented, and the score is sensitive to the literacy and education level of the patient. ${ }^{31,37,38}$ Furthermore, MMSE has a narrow dynamic performance range for normal individuals, creating a ceiling effect that limits the discrimination between high-scoring MCI patients and cognitively normal individuals. ${ }^{31,39,40}$

\section{MoCA}

In contrast to MMSE, MoCA was developed specifically to detect $\mathrm{MCI}^{29,40}$ and addresses some of the shortcomings of MMSE. ${ }^{39}$ It includes more complex tasks, including its test of executive function, which helps mitigate the ceiling effect. ${ }^{39} \mathrm{Al}-$ though education still affects MoCA scores, MoCA tries to address the issue by adding 1 point to the scores of patients who have 12 or fewer years of education. ${ }^{32,40}$

In its original validation study, MoCA performed better than the MMSE at distinguishing MCI from normal cognition, ${ }^{40}$ and its psychometric properties have since been further validated. ${ }^{29,31,41,42}$ Studies that directly compared the 
abilities of the MMSE and MoCA for distinguishing MCI from normal cognition reported sensitivities of $55 \%$ to $82 \%$ and specificities of $72 \%$ to $84 \%$ for the MMSE, ${ }^{43-49}$ and sensitivities of $77 \%$ to $96 \%$ and specificities of $73 \%$ to $95 \%$ for the MoCA. Meta-analyses have further suggested that MoCA may be the best MCI screening test available. $^{30,32}$

\section{Newer Cognitive Tests}

The mini-Addenbrooke's cognitive examination $(\mathrm{m}-\mathrm{ACE})^{34,50,51}$ may have equivalent or even a slightly improved performance than the MMSE and MoCA, but as a newer test, it is not as well validated.

Computerized cognitive tests have been developed, and once they are better validated, they may improve the convenience of cognitive screening and allow the collection of additional clinical variables, such as response time and eye-movement, and facilitate detection of cognitive changes over time. $^{52-56}$

\section{Laboratory Tests}

As cognitive screening test have limited specificity for different etiologies of MCI, and PiB-PET scan and CSF testing are too expensive and invasive, respectively, for use as screening tools, blood tests with reasonable specificity for the $\mathrm{AD}$ pathology could improve the efficiency of the evaluation process in the primary care setting.

So far, there is no blood test for biomarkers indicative of $\mathrm{AD}$ pathology. Several plasma biomarkers that are specific to the AD pathology, such as $\mathrm{A} \beta$ and tau, or indicative of nonspecific neuronal injury, such as neurofilament light chain are in development, and others are being explored. ${ }^{57-62}$ Similar to CSF biomarkers, ${ }^{8}$ plasma biomarkers may be most useful when used in combination.

\section{$\boldsymbol{A} \boldsymbol{\beta}$}

Developing an $A \beta$ blood test for routine clinical use proved to be challenging because of the low concentration of $A \beta$ in plasma, the peripheral production of $A \beta$ by platelets and the binding of $A \beta$ to plasma proteins. ${ }^{63}$ In addition, sample storage and processing can affect the quality and reproducibility of the results. ${ }^{64}$

While early studies of plasma $A \beta$ levels had inconsistent results, ${ }^{65,66}$ more recent studies were more promising: Nakamura et al,67 for example, reported a sensitivity of $97 \%$ and a specificity of $81 \%$, suggesting that a test for routine clinical use might become available in the foreseeable future. $^{67-69}$

\section{Tau}

Changes in CSF tau levels seem later than changes in CSF A $\beta$ levels, but there may still be a role for blood-based tau testing, as plasma tau levels correlate with $\mathrm{AD}, \mathrm{CSF}$ tau levels, $\mathrm{A} \beta$ and tau deposition in the brain as detected by PET imaging, and cortical thickness. ${ }^{6,70,71}$ Substantial development work remains necessary before a plasma-based tau test will become available. ${ }^{72}$

\section{Neurofilament Light Chain}

As a biomarker for nonspecific neuronal injury, plasma neurofilament light chain (NfL) testing may have value when used in combination with plasma $\mathrm{A} \beta$ and tau testing. The correlation between plasma and CSF NfL levels is better than the correlation of plasma and CSF tau levels. ${ }^{70}$ Plasma $\mathrm{NfL}$ levels are also higher in $\mathrm{A} \beta$-positive patients than in A $\beta$-negative patients. ${ }^{73}$ Plasma NfL tests are today mostly used in research.

\section{Alternative Diagnostic Modalities in Development}

There are other diagnostic modalities in earlier stages of research. Retinal scans that measure $A \beta$ deposition in the retina are currently in various stages of clinical trials in the US, Europe, and Australia. ${ }^{74}$ An earlier study had shown that retinal $\mathrm{A} \beta$ plaque burden correlates with central nervous system (CNS) A $\beta$ plaque burden. ${ }^{75}$ Since abnormal speech patterns and eye movements are potential signs of $\mathrm{AD}$, automated tools and computational techniques are being developed to analyze speech and eye movement recordings. ${ }^{76-78}$ Some researchers are studying olfactory dysfunction in $\mathrm{AD},{ }^{79-81}$ while others are analyzing electroencephalography patterns. ${ }^{82-84}$

\section{Impact on Downstream Patient Caseloads}

Based on US Census projections, there will be 98.8 million individuals 55 years and older in $2020 .{ }^{85}$ Extrapolating from published prevalence estimates, 10.7 million of these individuals will have MCI. ${ }^{26,88}$ Of the individuals with MCI, 6.6 million of them will have evidence of $\mathrm{A} \beta$ deposition in the brain. ${ }^{12}$

Using published sensitivities and specificities, ${ }^{45}$ cognitive testing of this general population with the 
Table 3. Projected Impact of Diagnostic Testing on Demand for Specialty Evaluation

\begin{tabular}{|c|c|c|c|c|}
\hline $\begin{array}{l}\text { Test for MCI Due } \\
\text { to } \mathrm{AD}\end{array}$ & $\begin{array}{l}\text { False Positives } \\
\text { (in Millions) }\end{array}$ & $\begin{array}{l}\text { True Positives } \\
\text { (in Millions) }\end{array}$ & $\begin{array}{l}\text { Number of Patients } \\
\text { Requiring Specialty } \\
\text { Referral (in } \\
\text { Millions) }\end{array}$ & $\begin{array}{l}\text { Proportion of Referred } \\
\text { Patients with } \\
\text { Confirmed MCI Due } \\
\text { to AD }\end{array}$ \\
\hline MMSE & 27.1 & 5.4 & 32.6 & $17 \%$ \\
\hline MMSE + plasma A $\beta$ & 5.2 & 5.3 & 10.4 & $51 \%$ \\
\hline $\mathrm{MoCA}$ & 21.9 & 5.6 & 27.5 & $20 \%$ \\
\hline MoCA + plasma $\mathrm{A} \beta$ & 4.2 & 5.4 & 9.6 & $56 \%$ \\
\hline
\end{tabular}

$\mathrm{A} \beta$, amyloid-beta; AD, Alzheimer disease; MCI, mild cognitive impairment; MMSE, mini-mental state exam; MoCA, Montreal Cognitive Assessment.

Patients with MCI due to $\mathrm{AD}$ have both MCI and evidence of $\mathrm{A} \beta$ deposition in the brain. We estimated that 10.7 million people in the 55+-year-old population in the United States in 2020 will have MCI. Of these, 6.6 million will also have evidence of A $\beta$ deposition.

MMSE alone would identify 5.4 million true-positive individuals with $\mathrm{MCI}$ due to $\mathrm{AD}$ (ie, have both MCI and $A \beta$ deposition) and 27.1 million falsepositive individuals. Based on the sensitivity and specificity of plasma $\mathrm{A} \beta$ testing reported by Nakamura et $\mathrm{al}^{67}$ the sequential addition of plasma $A \beta$ testing of the individuals who showed MCI on the MMSE could potentially reduce the number of false-positive cases to 5.2 million, while still detecting 5.3 million true-positive patients. Similarly, cognitive testing with $\mathrm{MoCA}^{45}$ alone would identify 5.6 million true-positive MCI due to $\mathrm{AD}$ patients and 21.9 million false-positive patients. MoCA, followed by plasma $\mathrm{A} \beta$ testing, ${ }^{67}$ would identify 5.4 million true-positive patients and 4.2 million false-positive patients.

The results (Table 3) shows how the MMSE will result in 5 false-positive cases for every 1 truepositive case detected. Replacing the MMSE with the MoCA will reduce the ratio to 4 false-positive cases for every 1 true-positive case detected. The addition of plasma $A \beta$ testing might reduce the ratio of false to true-positive cases to about 1 to 1 . In other words, it might prevent approximately $80 \%$ of the false-positive cases based on MMSE or MoCA testing from getting unnecessarily specialist referrals for confirmatory diagnosis.

\section{Discussion}

In our review of effective and efficient tools that could aid primary care providers to detect MCI due to $\mathrm{AD}$, we found that a large number of cognitive tests and other modalities exist but also that their utility is not well supported. Most of the cognitive tests are either not usable in primary care settings because of their length and complexity, or not well validated, or perform poorly for the detection of MCI. ${ }^{29-32}$ So far, only the MMSE and the MoCA have been shown to combine acceptable diagnostic accuracy and suitability for administration in primary care.

While cognitive tests perform reasonably well in determining the degree and pattern of cognitive impairment, they are inherently limited in their ability to identify the underlying etiology. A variety of diagnostic modalities attempt to differentiate the underlying etiology without expensive PiB-PET scans or invasive CSF testing, but none of them have been approved for clinical use yet. Currently, the most promising modalities are plasma biomarker tests, such as for $\mathrm{A} \beta, \tau$, and Nfl. ${ }^{65,67-71,73}$ While there have been technological challenges to developing these tests, recent studies demonstrated promising results and suggest that they will be available for routine clinical use in the future, possibly in combination with each other or some of the other biomarkers in development. ${ }^{57-62}$

Our calculations underscore that a combination of cognitive testing and plasma biomarkers is probably necessary for efficient testing for MCI due to $\mathrm{AD}$ in primary care settings. Both the MMSE and the MoCA when used alone would result in 4 to 5 false positives for every 1 true-positive case. The addition of plasma $A \beta$ testing would eliminate approximately $80 \%$ of these false-positive cases, reducing the number of patients who would require specialty referral by more than two-thirds. Our findings thus highlight the importance of having a reliable plasma biomarker test, especially since there is a shift toward a biological definition of $\mathrm{AD}$ from the historic clinical one. ${ }^{87}$ 
The aging US population coupled with the large reservoir of prevalent cases that would require evaluation when a DMT for $\mathrm{AD}$ is first approved imply a critical role for primary care providers, as they will have to prioritize patients with the greatest likelihood of benefiting from treatment for specialist visits. Intensified efforts to improve cognitive screening tools and to develop plasma biomarkers for routine use are dearly needed to enable primary care providers to play that critical role.

To see this article online, please go to: bttp://jabfm.org/content/ 32/6/931.full.

\section{References}

1. Selkoe DJ. Alzheimer disease and aducanumab: adjusting our approach. Nat Rev Neurol 2019;15:365366.

2. EISAI and Biogen Announce Detailed Results of Phase II Clinical Study of BAN2401 in Early Alzheimer's Disease At Alzheimer's Association International Conference (AAIC) 2018 [Press Release]. Eisai Co., Ltd. and Biogen Inc., July 262018.

3. Liu JL, Hlávka JP, Hillestad R, Mattke S. Assessing the preparedness of the U.S. health care system infrastructure for an Alzheimer's treatment. Santa Monica, CA: RAND Corporation; 2017.

4. Rabinovici GD, Gatsonis C, Apgar C, et al. Association of amyloid positron emission tomography with subsequent change in clinical management among medicare beneficiaries with mild cognitive impairment or dementia. JAMA 2019;321:1286-1294.

5. Cognat E, Mouton Liger F, Troussière AC, et al. What is the clinical impact of cerebrospinal fluid biomarkers on final diagnosis and management in patients with mild cognitive impairment in clinical practice? Results from a nation-wide prospective survey in France. BMJ Open 2019;9(5):e026380.

6. Rajan KB, Weuve J, Barnes LL, Wilson RS, Evans DA. Prevalence and incidence of clinically diagnosed Alzheimer's disease dementia from 1994 to 2012 in a population study. Alzheimers Dement 2019;15:1-7.

7. Lane CA, Hardy J, Schott JM. Alzheimer's disease. Eur J Neurol 2018;25:59-70.

8. Albert MS, DeKosky ST, Dickson D, et al. The diagnosis of mild cognitive impairment due to $\mathrm{Alz}^{-}$ heimer's disease: recommendations from the $\mathrm{Na}$ tional Institute on Aging-Alzheimer's Association workgroups on diagnostic guidelines for Alzheimer's disease. Alzheimers Dement 2011;7:270-279.

9. McKhann GM, Knopman DS, Chertkow H, et al. The diagnosis of dementia due to Alzheimer's disease: recommendations from the National Institute on Aging-Alzheimer's Association workgroups on diagnostic guidelines for Alzheimer's disease. Alzheimers Dement 2011;7:263-269.

10. Sperling RA, Aisen PS, Beckett LA, et al. Toward defining the preclinical stages of Alzheimer's disease: recommendations from the National Institute on Aging-Alzheimer's Association workgroups on diagnostic guidelines for Alzheimer's disease. Alzheimers Dement 2011;7:280-292.

11. Jack CR Jr, Knopman DS, Jagust WJ, et al. Tracking pathophysiological processes in Alzheimer's disease: an updated hypothetical model of dynamic biomarkers. Lancet Neurol 2013;12:207-216.

12. Petersen RC, Aisen P, Boeve BF, et al. Mild cognitive impairment due to Alzheimer disease in the community. Ann Neurol 2013;74:199-208.

13. Knopman DS, Petersen RC. Mild cognitive impairment and mild dementia: a clinical perspective. Mayo Clin Proc 2014;89:1452-1459.

14. Safety and Efficacy study of gantenerumab in participants with early Alzheimer's disease (AD). Available from: https://ClinicalTrials.gov/show/NCT03443973. Accessed March 17, 2019.

15. Efficacy and Safety study of gantenerumab in participants with early Alzheimer's disease (AD). Available from: https://ClinicalTrials.gov/show/NCT03444870. Accessed March 17, 2019.

16. A study to confirm safety and efficacy of BAN2401 in participants with early Alzheimer's disease. Available from: https://ClinicalTrials.gov/show/NCT03887455. Accessed June 22, 2019.

17. A study of LY3002813 in participants with early symptomatic Alzheimer's disease (TRAILBLAZERALZ). Available from: https://ClinicalTrials.gov/ show/NCT03367403. Accessed March 17, 2019.

18. A study to evaluate the efficacy and safety of ABBV$8 \mathrm{E} 12$ in subjects with early Alzheimer's disease. Available from: https:/ClinicalTrials.gov/show/ NCT02880956. Accessed March 17, 2019.

19. A study to evaluate the efficacy and safety of RO7105705 in patients with prodromal to mild Alzheimer's disease. Available from: https://ClinicalTrials.gov/show/NCT03289143. Accessed March $17,2019$.

20. A 24-month study to evaluate the efficacy and safety of E2609 in subjects with early Alzheimer's disease (MissionAD2). Available from: https://ClinicalTrials.gov/show/NCT03036280. Accessed March $17,2019$.

21. A study of CNP520 versus placebo in participants at risk for the onset of clinical symptoms of Alzheimer's disease. Available from: https://ClinicalTrials.gov/ show/NCT03131453. Accessed March 17, 2019.

22. A study of CAD106 and CNP520 versus placebo in participants at risk for the onset of clinical symptoms of Alzheimer's disease. Available from: https:// ClinicalTrials.gov/show/NCT02565511. Accessed March 17, 2019.

23. 24 months safety and efficacy study of AADvac1 in patients with mild Alzheimer's disease. Available from: https:/ClinicalTrials.gov/show/NCT02579252. Accessed March 17, 2019. 
24. Cummings J, Lee G, Ritter A, Zhong K. Alzheimer's disease drug development pipeline: 2018. Alzheimers Dement (N Y) 2018;4:195-214.

25. Khan A, Corbett A, Ballard C. Emerging treatments for Alzheimer's disease for non-amyloid and non-tau targets. Expert Rev Neurother 2017;17:683-695.

26. Petersen RC, Lopez O, Armstrong MJ, et al. Practice guideline update summary: mild cognitive impairment: report of the Guideline development, dissemination, and implementation subcommittee of the American Academy of Neurology. Neurology 2018;90:126-135.

27. Cordell CB, Borson S, Boustani M, et al. Alzheimer's Association recommendations for operationalizing the detection of cognitive impairment during the Medicare Annual Wellness Visit in a primary care setting. Alzheimers Dement 2013;9:141-150.

28. Gerontological Society of America (GSA) workgroup on cognitive impairment detection and earlier diagnosis. KAER-A 4-step process to detecting cognitive impairment and earlier diagnosis of dementia. Available from: https://www.geron.org/ images/gsa/kaer/gsa-kaer-toolkit.pdf. Published 2017. Accessed March 3, 2019.

29. Lin JS, O'Connor E, Rossom RC, et al. U.S. Preventive Services Task Force Evidence Syntheses, formerly Systematic Evidence Reviews. In: Screening for cognitive impairment in older adults: an evidence update for the U.S. Preventive Services Task Force. Rockville (MD): Agency for Healthcare Research and Quality (US); 2013.

30. Tsoi KK, Chan JY, Hirai HW, Wong SY, Kwok TC. Cognitive tests to detect dementia: a systematic review and meta-analysis. JAMA Intern Med 2015; 175:1450-1458.

31. Lonie JA, Tierney KM, Ebmeier KP. Screening for mild cognitive impairment: a systematic review. Int J Geriatr Psychiatry 2009;24:902-915.

32. Ozer S, Young J, Champ C, Burke M. A systematic review of the diagnostic test accuracy of brief cognitive tests to detect amnestic mild cognitive impairment. Int J Geriatr Psychiatry 2016;31:1139-1150.

33. Weissberger GH, Strong JV, Stefanidis KB, Summers MJ, Bondi MW, Stricker NH. Diagnostic accuracy of memory measures in Alzheimer's dementia and mild cognitive impairment: a systematic review and metaanalysis. Neuropsychol Rev 2017;27:354-388.

34. Williamson JC, Larner AJ. MACE for the diagnosis of dementia and MCI: 3-year pragmatic diagnostic test accuracy study. Dement Geriatr Cogn Disord 2018;45:300-307.

35. Folstein MF, Folstein SE, McHugh PR. "Mini-mental state". A practical method for grading the cognitive state of patients for the clinician. J Psychiatr Res 1975;12:189-198.

36. Folstein M, Folstein S. Invited reply to "The death knoll for the MMSE: has it outlived its purpose?". J Geriatr Psychiatry Neurol 2010;23:158-159.
37. Carnero-Pardo C. Should the mini-mental state examination be retired? Neurologia 2014;29:473-481.

38. Nieuwenhuis-Mark RE. The death knoll for the MMSE: has it outlived its purpose? J Geriatr Psychiatry Neurol 2010;23:151-157.

39. Trzepacz PT, Hochstetler H, Wang S, Walker B, Saykin AJ. Relationship between the Montreal Cognitive Assessment and Mini-Mental State Examination for assessment of mild cognitive impairment in older adults. BMC Geriatr 2015;15:107.

40. Nasreddine ZS, Phillips NA, Bédirian V, et al. The Montreal Cognitive Assessment, MoCA: a brief screening tool for mild cognitive impairment. J Am Geriatr Soc 2005;53:695-699.

41. Julayanont P, Brousseau M, Chertkow H, Phillips N, Nasreddine ZS. Montreal Cognitive Assessment Memory Index Score (MoCA-MIS) as a predictor of conversion from mild cognitive impairment to $\mathrm{Alz}-$ heimer's disease. J Am Geriatr Soc 2014;62:679684.

42. Lam B, Middleton LE, Masellis M, et al. Criterion and convergent validity of the Montreal Cognitive Assessment with screening and standardized neuropsychological testing. J Am Geriatr Soc 2013;61: 2181-2185.

43. Mellor D, Lewis M, McCabe M, et al. Determining appropriate screening tools and cut-points for cognitive impairment in an elderly Chinese sample. Psychol Assess 2016;28:1345-1353.

44. Luis CA, Keegan AP, Mullan M. Cross validation of the Montreal Cognitive Assessment in community dwelling older adults residing in the Southeastern US. Int J Geriatr Psychiatry 2009;24:197-201.

45. Roalf DR, Moberg PJ, Xie SX, Wolk DA, Moelter ST, Arnold SE. Comparative accuracies of two common screening instruments for classification of Alzheimer's disease, mild cognitive impairment, and healthy aging. Alzheimers Dement 2013;9:529-537.

46. Ciesielska N, Sokołowski R, Mazur E, Podhorecka M, Polak-Szabela A, Kedziora-Kornatowska K. Is the Montreal Cognitive Assessment (MoCA) test better suited than the Mini-Mental State Examination (MMSE) in mild cognitive impairment (MCI) detection among people aged over 60? Meta-analysis. Psychiatr Pol 2016;50:1039-1052.

47. Freitas S, Simões MR, Alves L, Santana I. Montreal cognitive assessment: validation study for mild cognitive impairment and Alzheimer disease. Alzheimer Dis Assoc Disord 2013;27:37-43.

48. Fujiwara Y, Suzuki H, Yasunaga M, et al. Brief screening tool for mild cognitive impairment in older Japanese: validation of the Japanese version of the Montreal Cognitive Assessment. Geriatr Gerontol Int 2010;10:225-232.

49. Tiffin-Richards FE, Costa AS, Holschbach B, et al. The Montreal Cognitive Assessment (MoCA)—A sensitive screening instrument for detecting cogni- 
tive impairment in chronic hemodialysis patients. PLoS One 2014;9(10):e106700.

50. Hsieh S, McGrory S, Leslie F, et al. The MiniAddenbrooke's Cognitive Examination: a new assessment tool for dementia. Dement Geriatr Cogn Disord 2015;39:1-11.

51. Larner AJ. MACE versus MoCA: equivalence or superiority? Pragmatic diagnostic test accuracy study. Int Psychogeriatr 2017;29:931-937.

52. Berg JL, Durant J, Léger GC, Cummings JL, Nasreddine Z, Miller JB. Comparing the electronic and standard versions of the Montreal Cognitive Assessment in an outpatient memory disorders clinic: a validation study. J Alzheimers Dis 2018;62:93-97.

53. Wild K, Howieson D, Webbe F, Seelye A, Kaye J. Status of computerized cognitive testing in aging: a systematic review. Alzheimers Dement 2008;4:428437.

54. Darby DG, Fredrickson J, Pietrzak RH, Maruff P, Woodward M, Brodtmann A. Reliability and usability of an internet-based computerized cognitive testing battery in community-dwelling older people. Computers Human Behav 2014;30:199-205.

55. Buckley RF, Sparks KP, Papp KV, et al. Computerized cognitive testing for use in clinical trials: a comparison of the NIH Toolbox and Cogstate C3 batteries. J Prev Alzheimers Dis 2017;4:3-11.

56. Denboer JW, Nicholls C, Corte C, Chestnut K. National Institutes of Health Toolbox Cognition Battery. Arch Clin Neuropsychol 2014;29:692-694.

57. Yang H, Lyutvinskiy Y, Herukka SK, Soininen H, Rutishauser D, Zubarev RA. Prognostic polypeptide blood plasma biomarkers of Alzheimer's disease progression. J Alzheimers Dis 2014;40:659-666.

58. Hye A, Riddoch-Contreras J, Baird AL, et al. Plasma proteins predict conversion to dementia from prodromal disease. Alzheimers Dement 2014;10:799807.e792.

59. DeMarshall CA, Nagele EP, Sarkar A, et al. Detection of Alzheimer's disease at mild cognitive impairment and disease progression using autoantibodies as blood-based biomarkers. Alzheimers Dement (Amst) 2016;3:51-62.

60. Yamamoto-Imoto H, Zamolodchikov D, Chen ZL, et al. A novel detection method of cleaved plasma high-molecular-weight kininogen reveals its correlation with Alzheimer's pathology and cognitive impairment. Alzheimers Dement (Amst) 2018;10:480 489.

61. Varma VR, Varma S, An Y, et al. Alpha-2 macroglobulin in Alzheimer's disease: a marker of neuronal injury through the RCAN1 pathway. Mol Psychiatry 2017;22:13-23.

62. Zarrouk A, Debbabi M, Bezine M, et al. Lipid biomarkers in Alzheimer's disease. Curr Alzheimer Res 2018;15:303-312.
63. Chintamaneni M, Bhaskar M. Biomarkers in Alzheimer's disease: a review. ISRN Pharmacol 2012;2012: 984786.

64. Donohue MC, Moghadam SH, Roe AD, et al. Longitudinal plasma amyloid beta in Alzheimer's disease clinical trials. Alzheimers Dement 2015;11:10691079.

65. Olsson B, Lautner R, Andreasson U, et al. CSF and blood biomarkers for the diagnosis of Alzheimer's disease: a systematic review and meta-analysis. Lancet Neurol 2016;15:673-684.

66. Ritchie C, Smailagic N, Noel-Storr AH, et al. Plasma and cerebrospinal fluid amyloid beta for the diagnosis of Alzheimer's disease dementia and other dementias in people with mild cognitive impairment (MCI). Cochrane Database Syst Rev 2014(6): Cd008782.

67. Nakamura A, Kaneko N, Villemagne VL, et al. High performance plasma amyloid- $\beta$ biomarkers for $\mathrm{Alz}$ heimer's disease. Nature 2018;554:249-254.

68. Fandos N, Perez-Grijalba V, Pesini P, et al. Plasma amyloid beta $42 / 40$ ratios as biomarkers for amyloid beta cerebral deposition in cognitively normal individuals. Alzheimers Dement (Amst) 2017;8:179-187.

69. Tzen KY, Yang SY, Chen TF, et al. Plasma A $\beta$ but not tau is related to brain $\mathrm{PiB}$ retention in early Alzheimer's disease. ACS Chem Neurosci 2014;5: $830-836$.

70. Blennow K. A review of fluid biomarkers for Alzheimer's disease: moving from CSF to blood. Neurol Ther 2017;6(Suppl 1):15-24.

71. Mielke MM, Hagen CE, Xu J, et al. Plasma phospho-tau181 increases with Alzheimer's disease clinical severity and is associated with tau- and amyloidpositron emission tomography. Alzheimers Dement 2018;14:989-997.

72. Chen Z, Mengel D, Keshavan A, et al. Learnings about the complexity of extracellular tau aid development of a blood-based screen for Alzheimer's disease. Alzheimers Dement 2019;15:487-496.

73. Mattsson N, Andreasson U, Zetterberg H, Blennow $\mathrm{K}$. Association of plasma neurofilament light with neurodegeneration in patients with Alzheimer disease. JAMA Neurol 2017;74:557-566.

74. Abbasi J. A retinal Scan for Alzheimer disease. JAMA 2017;318:1314.

75. Koronyo-Hamaoui M, Koronyo Y, Ljubimov AV, et al. Identification of amyloid plaques in retinas from Alzheimer's patients and noninvasive in vivo optical imaging of retinal plaques in a mouse model. NeuroImage 2011;54(Suppl 1):S204-S217.

76. Garrard P, Nemes V, Nikolic D, Barney A. Motif discovery in speech: application to monitoring $\mathrm{Alz}^{-}$ heimer's disease. Curr Alzheimer Res 2017;14:951959.

77. Khodabakhsh A, Demiroglu C. Analysis of speechbased measures for detecting and monitoring Alzhei- 
mer's disease. Methods Mol Biol 2015;1246:159173.

78. Beltrán J, Garcia-Vazquez MS, Benois-Pineau J, Gutierrez-Robledo LM, Dartigues JF. Computational techniques for eye movements analysis towards supporting early diagnosis of Alzheimer's disease: A Review. Comput Math Methods Med 2018; 2018:2676409.

79. Silva MME, Mercer PBS, Witt MCZ, Pessoa RR. Olfactory dysfunction in Alzheimer's disease systematic review and meta-analysis. Dement Neuropsychol 2018;12:123-132.

80. Jung HJ, Shin IS, Lee JE. Olfactory function in mild cognitive impairment and Alzheimer's disease: A meta-analysis. Laryngoscope 2019;129:362-369.

81. Velayudhan L. Smell identification function and Alzheimer's disease: a selective review. Curr Opin Psychiatry 2015;28:173-179.

82. Horvath A, Szucs A, Csukly G, Sakovics A, Stefanics G, Kamondi A. EEG and ERP biomarkers of Alz- heimer's disease: a critical review. Front Biosci (Landmark Ed) 2018;23:183-220.

83. Nobukawa S, Yamanishi T, Nishimura H, Wada Y, Kikuchi M, Takahashi T. Atypical temporal-scalespecific fractal changes in Alzheimer's disease EEG and their relevance to cognitive decline. Cogn Neurodyn 2019;13:1-11.

84. Kanda PAM, Oliveira EF, Fraga FJ. EEG epochs with less alpha rhythm improve discrimination of mild Alzheimer's. Computer methods and programs in biomedicine 2017;138:13-22.

85. U.S. Census Bureau, Population Division. Projected 5-Year Age Groups and Sex Composition: Main Projections Series for the United States, 2017-2060. Available from: https:/www.census.gov/data/tables/ 2017/demo/popproj/2017-summary-tables.html. Accessed January 31, 2019.

86. Gauthier S, Reisberg B, Zaudig M, et al. Mild cognitive impairment. Lancet 2006;367:1262-1270.

87. Will Europe be ready for the treatment of Alzheimer's disease? Lancet Neurol 2018;17:1025. 